\title{
Power Performance of an Inversely Tapered Wind Rotor and its Air Flow Visualization Analysis Using Particle Image Velocimetry (PIV)
}

\author{
Churchill Otieno Saoke ${ }^{1}$, Joseph Ngugi Kamau ${ }^{1}$, Robert Kinyua ${ }^{1}$, Yoshifumi Nishizawa ${ }^{2}$, \\ Izumi Ushiyama ${ }^{2}$
}

${ }^{1}$ Department of Physics, Jomo Kenyatta University of Agriculture and Technology, Nairobi, Kenya

${ }^{2}$ Division of Renewable Energy, Ashikaga Institute of Technology, Ashikaga, Japan

Email address:

winsaoke@gmail.com (C. O. Saoke)

To cite this article:

Churchill Otieno Saoke, Joseph Ngugi Kamau, Robert Kinyua, Yoshifumi Nishizawa, Izumi Ushiyama. Power Performance of an Inversely Tapered Wind Rotor and its Air Flow Visualization Analysis Using Particle Image Velocimetry (PIV). American Journal of Physics and Applications. Vol. 3, No. 1, 2015, pp. 6-14. doi: 10.11648/j.ajpa.20150301.12

\begin{abstract}
Wind turbine rotors capture energy from moving wind, their capacity to perform this function depends on the coefficient of power $(\mathrm{Cp})$ of the rotor. Through proper aerodynamic design, a rotor's performance can be optimized to take advantage of the smallest available wind speed at any time to produce energy. In this research a computational fluid dynamics simulation was performed to model the best optimum dimensions of an inversely tapered rotor blade using Clark Y airfoil type rotor of $0.6 \mathrm{~m}$ diameter. The optimal design values obtained include; tip speed ratio (TSR) of 2.5 , lift coefficient to drag coefficient ratio of 1.1 and pitch angle of 8 degrees Using blade element momentum (BEM), the wing profile of each section of the blade was calculated and designed. The unique inverse tapering was done to achieve a better efficiency at the low wind speed range. This was used to fabricate a three blade rotor using carbon composites which was tested in the wind tunnel for $\mathrm{Cp}$. Results showed very good performance of the inverse tapered type as compared with the tapered rotors. The maximum coefficient of power for the inversely tapered was found to be 0.313 at $8 \mathrm{~m} / \mathrm{s}$. Visualization test and particle image velocimetry (P.I.V). analysis showed that the inversely tapered rotor is more effective in converting wind power into shaft power than the tapered.
\end{abstract}

Keywords: Horizontal Axis Small Wind Turbine, Inversely Tapered, Flow Visualization, Coefficient of Power

\section{Introduction}

\subsection{Background}

Exponential rise of the problems related to the environment and limited fossil energy at present has enabled much attention to shift to wind energy as a limitless source of energy that has no environmental pollution. Moreover, the world population is expected to grow some 9 billion around the year 2050. With such a rapid expansion of the population, the demand for food, water, energy and pollution of the environment with increase exponentially. Therefore, a priority issue for 21 st century is to assure enough energy and water in the developing countries needed for increasing agricultural output to meet the expected demand.. Development of wind power equipment will be essential in achieving these power needs. This will require the use of appropriate technology to reduce cost and localize manufacture to developing countries because such technologies are perfectly applicable to the individual conditions of the people of a particular region (Maeda K. et. al., 1995).

The large-scale wind turbines with the grid connection system operated in wind farms are being used for the power generation in many advanced nations. On the other hand, the small-scale wind turbines have been used as the independent source of electricity regardless of the places. In recent years, these small wind turbines of a diameter under $2 \mathrm{~m}$ are employed for street lights, park lights, environmental monuments, power sources for emergencies and teaching materials. Because such small wind turbines are usually installed in urban areas, the noise generate from rotor, the failures due to the sudden changes of the wind direction and wind speed which are peculiar to those areas became 
particularly noticeable these days with increase of the installation.

While there are many papers on the small wind turbine rotors with high tip speed ratio adjusted for conventional generators, a number of the paper systematically dealing the rotor shapes applied for low tip speed ratio is very small.

\subsection{Blade Design and Experimental Models}

Nishizawa et al., (2013) did a study on the shapes of rotor for horizontal axis small wind turbine using sail wing from developing countries, this was done with four types of blade models namely; the triangle type, the tapered type, the straight type and the inversely tapered type; all of which the number of blades was six. A maximum power coefficient of Cpmax $=0.22$ was obtained when the shape of blade was inversely tapered type. However, the solidity of these experimental models was 0.29 (Nishizawa Y. et al., 2008).

Saoke et. al. (2014) looked at the wind tunnel performance of a small tapered wind turbine rotor. The experimental was based on the following design values which were developed from blade element momentum theory. The design values included; the design tip speed ratio is $\lambda_{d}=2.5$, number of blade is three, and a rotor with tapered blades in which the chord length increases from the root towards the tip, lift-drad coefficients' ratio $(\mathrm{Cl} / \mathrm{Cd})$ ratio 1.1 and rotational speed of $750 \mathrm{rpm}$. Saoke (2014) found exciting results on the performance of this turbine in the wind tunnel, the coefficient of power was found as 0.29 . The study recommends more work to be done on the blade geometry to optimize its $\mathrm{Cp}$ value.

\section{Methodology}

\subsection{Theoretical Optimization}

To ensure maximum aerodynamic optimization, the blade shape calculated was such that there is minimum wake rotation by choosing a rotational speed of 750 revolutions per minute; this is informed by the fact that as the rotor is allowed to rotate very quickly the energy loss due to wake rotation is minimized. Minimum or no wake rotation means that the induction factor was chosen $a^{\prime}$ had to be set at zero. The axial other induction factor $a$ was chosen to be $1 / 3$ in each annular stream tube this is the maximum value expected based on the Beltz limit. Some of the assumptions made included;

i. There is no drag; thus the drag coefficient is zero

ii. There are no loses due to finite number of blades i.e no tip loss

With these assumptions, the simplified equations from the blade element momentum were used to calculate the dimensions of the blade the deign values used are as shown in the table 1 below;

Table 1. Selected design parameters of the wind turbine.

\begin{tabular}{ll}
\hline Rotor diameter[mm] & 600.0 \\
Number of blades & 3.0 \\
Generator [rpm] & 750.0 \\
Power rating [W] & 25.0 \\
Design tip speed ratio & 2.5 \\
Angle of Attack & $8^{\circ}$ \\
Lift coefficient & 1.1 \\
Airfoil type & Clark Y \\
\hline
\end{tabular}

The linearization was performed using the chord length and pitch angle values at $30 \%$ and $10 \%$ span points. These points were selected because their theoretical values were tending towards a linear trend. The choice of the points for linearization must be done with a lot of care as a poor decision would lead to a totally different rotor dimensions and hence affecting the rotor efficiency. The selected linearized pitch angle and chord lengths are in table 2. As can be seen from table 2, the chord length increases from the root to the tip; this gives rise to the inversely tapered rotor blade. It is the inverse of the tapered type that was developed by saoke et. al. (2014). The idea is to try to manipulate the shape of the blade such that it maximizes the lift force and minimized the effect of drag as much as possible. The impact on air flow of inversing the blade shape will be seen in the next section through a visualization experiment.

Table 2. Linearized wind profile dimensions for the inversely tapered type.

\begin{tabular}{lllll}
\hline Linearized wind profile dimensions & & \\
\hline Span point (\%) & Section point (Local radius m) & Pitch angle (degree) & 3-bladed (mm) & Magnification (200mm) \\
\hline 0 & 0 & 25.27 & 0.0712 & 0.356 \\
10 & 0.03 & 23.3401 & 0.07888 & 0.394 \\
20 & 0.06 & 21.4102 & 0.08656 & 0.433 \\
30 & 0.09 & 19.4803 & 0.09424 & 0.471 \\
40 & 0.12 & 17.5504 & 0.10192 & 0.510 \\
50 & 0.15 & 15.6205 & 0.1096 & 0.548 \\
60 & 0.18 & 13.6906 & 0.11728 & 0.586 \\
70 & 0.21 & 11.7607 & 0.12496 & 0.625 \\
80 & 0.24 & 9.8308 & 0.13264 & 0.663 \\
90 & 0.27 & 7.9009 & 0.14032 & 0.702 \\
100 & 0.3 & 5.971 & 0.148 & 0.74 \\
\hline
\end{tabular}




\subsection{Wind Tunnel Experiments}

The wind tunnel used for our experiment is of the Effel type with exit of $1.05[\mathrm{~m}] \times 1.05[\mathrm{~m}]$. The wind speed is adjustable between $2 \mathrm{~m} / \mathrm{s}$ and $20 \mathrm{~m} / \mathrm{s}$. An induction motor is employed as load in the experiment and the synchronized frequency is controlled by an inverter. For arbitrary determined frequencies, from high rotational speed for no load condition to lower rotational speed for gradually loaded condition, corresponding torque and rotational speed are measured by a torque converter and a revolution counter. Figure 1 shows the layout of the experimental apparatus while Figure 2 shows the turbine being tested in the wind tunnel. In the experiment of all rotors, the wind speed in the wind tunnel is set at $10 \mathrm{~m} / \mathrm{s}$ and the torque corresponding to the revolution is measured by gradually increasing the load.
From the results of the experiment and using equations 1 and 2 , the power coefficient $\mathrm{Cp}$ and the tip speed ratio $\lambda$ are calculated to obtain the power characteristics for different blade types.

$$
\begin{gathered}
\text { Power coefficient: } C_{P}=\frac{2 \pi n / 60 Q}{1 / 2 \rho A V^{3}} \\
\text { Tip speed ratio: } \lambda=\frac{2 \pi R n / 60}{V}
\end{gathered}
$$

Where; $C_{P}$ - Power coefficient, $n$ - Rotational speed, $\rho$ Air density, $V$ - Wind speed, $A$ - Rotor area, $R$ - Rotor radius, $\lambda$ - Tip Speed Ratio, $Q$ - Torque

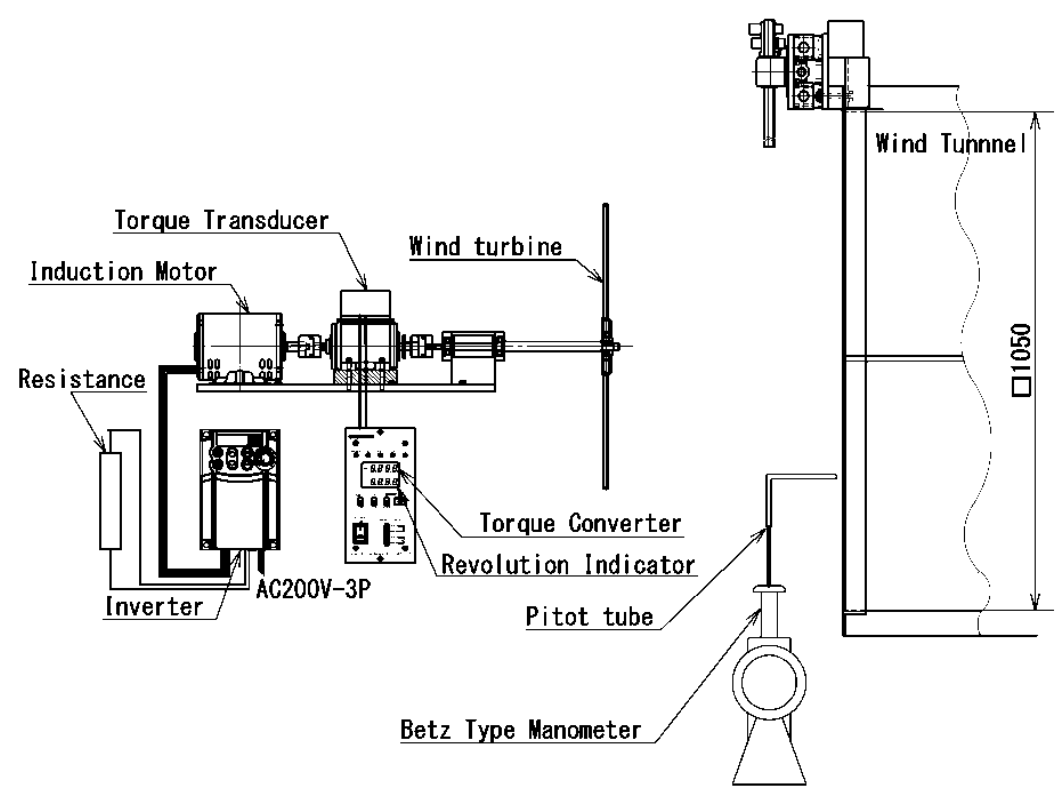

Figure 1. Schematic diagram of the wind tunnel setup.

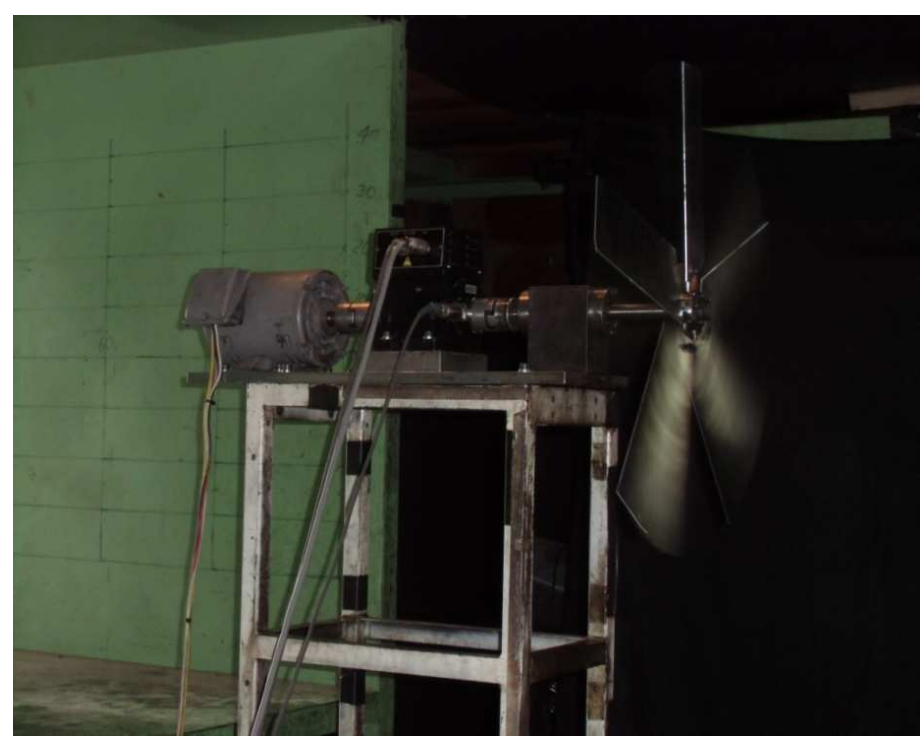

Figure 2. Turbine undergoing torque test in the wind tunnel. 


\section{Test of Air Flow Around Rotor}

The layout of the apparatus for visualization is shown in Figure 3. As visualization test, wind speed of wind tunnel set at $8[\mathrm{~m} / \mathrm{s}]$. The rotational speed of each of turbine was configured when each of experimental wind turbine obtain maximum power coefficient. An induction motor is employed as load in the experiment and the synchronized frequency is controlled by an inverter.

A mechanical smoke was generated by a tracer. This was

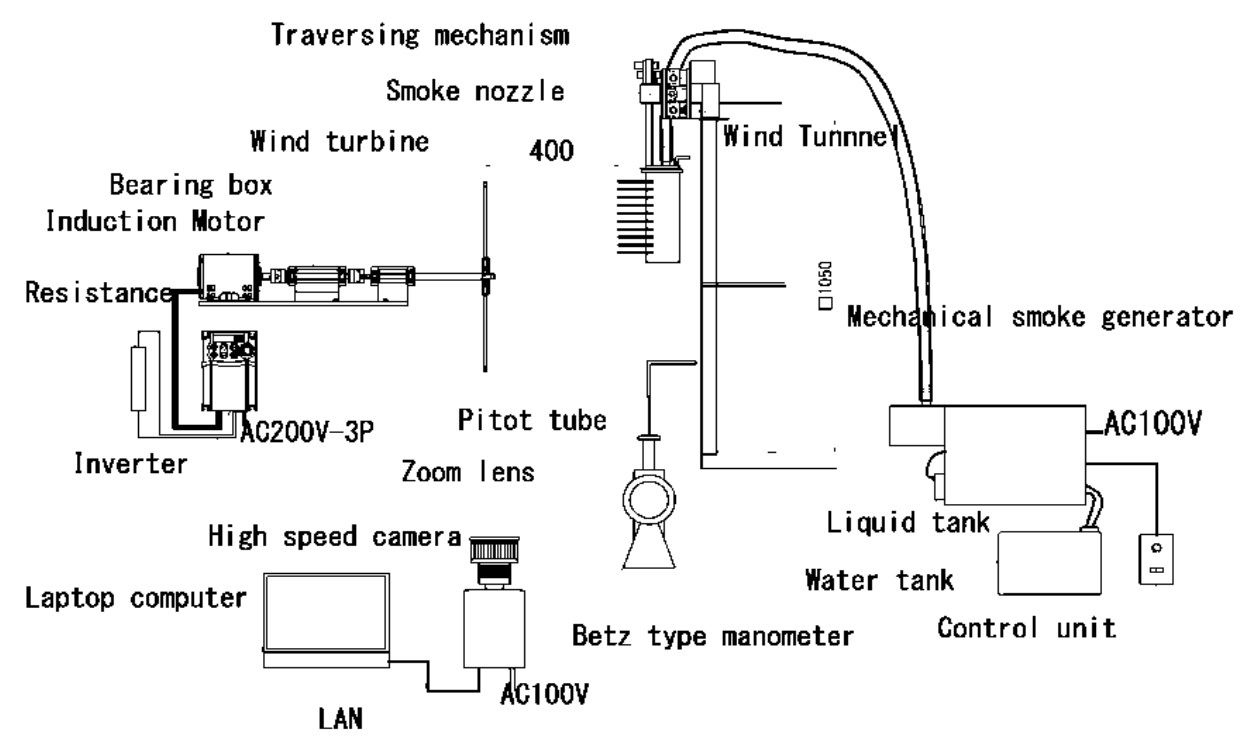

Figure 3. Layout of the apparatus for visualization.

\subsection{Results and Discussions}

the inversely tapered wind turbine rotor at $8 \mathrm{~m} / \mathrm{s}$ and $10 \mathrm{~m} / \mathrm{s}$

Tables 3 and 4 give the results of the wind tunnel testing of discharged a through smoke nozzle. Halogen a lamp of number of 6 was used as the source of illumination was used; with the aid of a high speed camera, shots were taken after every two rotation of the wind turbine. Short video clips of these shots were produced in laptop computer. The sampling frequency of high speed camera was set at $500[\mathrm{~Hz}]$. These movie files were uploaded to a visualization software where the analysis of vector airflow around each experimental wind turbines was done.

Table 3. Wind tunnel data for inversely tapered rotor at $8 \mathrm{~m} / \mathrm{s}$ wind speed.

\begin{tabular}{|c|c|c|c|c|c|}
\hline Wind speed $8[\mathrm{~m} / \mathrm{s}]$ & ROTOR RADIUS & $0.3[\mathrm{~m}]$ & AREA & $0.2827433\left[\mathrm{~m}^{2}\right]$ & \\
\hline Air density & $1.184337074\left[\mathrm{~kg} / \mathrm{m}^{3}\right]$ & Temperature & & $25\left[{ }^{\circ} \mathrm{C}\right]$ & \\
\hline ROTATIONAL SPEED [rpm] & TORQUE [Nm] & TSR & $\mathbf{C q}$ & $\mathbf{C p}$ & POWER[W] \\
\hline 943 & 0 & 3.70315234 & 0 & 0 & 0 \\
\hline 900 & 0.039 & 3.53429174 & 0.0121318 & 0.0428774 & 3.6756634 \\
\hline 801 & 0.167 & 3.14551964 & 0.051949 & 0.1634067 & 14.008047 \\
\hline 700 & 0.269 & 2.74889357 & 0.0836784 & 0.230023 & 19.71873 \\
\hline 649 & 0.337 & 2.54861704 & 0.1048313 & 0.2671748 & 22.903572 \\
\hline 624 & 0.366 & 2.45044227 & 0.1138524 & 0.2789887 & 23.916317 \\
\hline 600 & 0.391 & 2.35619449 & 0.1216292 & 0.286582 & 24.567255 \\
\hline 574 & 0.43 & 2.25409273 & 0.133761 & 0.3015097 & 25.84693 \\
\hline 549 & 0.467 & 2.15591796 & 0.1452707 & 0.3131916 & 26.848365 \\
\hline 525 & 0.468 & 2.06167018 & 0.1455817 & 0.3001415 & 25.729644 \\
\hline 500 & 0.485 & 1.96349541 & 0.15087 & 0.2962325 & 25.394541 \\
\hline 451 & 0.5 & 1.77107286 & 0.155536 & 0.2754657 & 23.614305 \\
\hline 299 & 0.422 & 1.17417025 & 0.1312724 & 0.1541362 & 13.213329 \\
\hline 199 & 0.329 & 0.78147117 & 0.1023427 & 0.0799779 & 6.8561071 \\
\hline 99 & 0.22 & 0.38877209 & 0.0684359 & 0.026606 & 2.2807963 \\
\hline
\end{tabular}


Table 4. Wind tunnel data for inversely tapered rotor at $10 \mathrm{~m} / \mathrm{s}$ wind speed.

\begin{tabular}{|c|c|c|c|c|c|}
\hline \multirow{3}{*}{$\begin{array}{l}\text { WIND SPEED } 10[\mathrm{~m} / \mathrm{s}] \\
\text { AIR DENSITY } 1.180369173[\mathrm{~kg} / \mathrm{m}\end{array}$} & ROTOR RADIUS 0.3[m] & \multirow{2}{*}{\multicolumn{2}{|c|}{$\begin{array}{l}\text { AREA } 0.28 \\
\text { TEMPERATURE } 26\left[{ }^{\circ} \mathrm{C}\right]\end{array}$}} & & \multirow[b]{3}{*}{ POWER [W] } \\
\hline & & & & \multirow[b]{2}{*}{$\mathbf{C p}$} & \\
\hline & TORQUE[Nm] & TSR & $\mathrm{Cq}$ & & \\
\hline 1161 & 0 & 3.64738907 & 0 & 0 & 0 \\
\hline 1000 & 0.233 & 3.14159265 & 0.046543 & 0.1462192 & 24.399703 \\
\hline 900 & 0.382 & 2.82743339 & 0.0763066 & 0.2157517 & 36.002652 \\
\hline 799 & 0.522 & 2.51013253 & 0.1042723 & 0.2617373 & 43.676306 \\
\hline 751 & 0.586 & 2.35933608 & 0.1170567 & 0.276176 & 46.085698 \\
\hline 701 & 0.662 & 2.20225645 & 0.1322381 & 0.2912221 & 48.596459 \\
\hline 651 & 0.717 & 2.04517682 & 0.1432246 & 0.2929197 & 48.879726 \\
\hline 626 & 0.744 & 1.966637 & 0.148618 & 0.2922777 & 48.772598 \\
\hline 601 & 0.761 & 1.88809718 & 0.1520138 & 0.2870169 & 47.894732 \\
\hline 551 & 0.763 & 1.73101755 & 0.1524134 & 0.2638302 & 44.025546 \\
\hline 399 & 0.689 & 1.25349547 & 0.1376315 & 0.1725204 & 28.788613 \\
\hline 201 & 0.454 & 0.63146012 & 0.0906889 & 0.0572665 & 9.5560965 \\
\hline 99 & 0.314 & 0.31101767 & 0.0627232 & 0.019508 & 3.2553183 \\
\hline
\end{tabular}

\subsection{Torque and Power Coefficient Curves}

The correlation of power and torque coefficient and Tip Speed Ratio for the different wind speeds are as shown in the figure 4 and 5 respectively. These power curves are very instrumental in assessing the capacity of a turbine to capture wind energy. From theory, it is known that the tip speed ratio of a turbine helps to maximize the power output and efficiency of the wind turbine in that if a rotor spins too slowly, a lot of wind will pass through the gaps between the blades rather than giving energy to the turbine. Also if the blades spin too quickly, they could create too much turbulent air or act as a solid wall against the wind. So, the Tip Speed Ratio is helpful in maximizing the turbine's efficiency.

From the power curves, the power coefficient is optimum at around the design Tip Speed ratio, meaning that at this peak the turbine captures more power. Nevertheless, when the turbine is operating at extremes from the design value then the $C_{p}$ is lowered because either more wind is passing through the blades without being slowed by the blades or the blades are moving too fast that they create a solid wall that blocks the wind like a wall.

For the different wind speeds tested, the inverse tapered rotor blade gave power coefficient maxima are as shown in figure 4. This is a higher $\mathrm{Cp}$ value when compared with the results of the tapered type from saoke (2014).

Although the design wind speed for the turbine was $8 \mathrm{~m} / \mathrm{s}$, looking at the results the turbine's capacity to capture power at lower wind speeds was still considerable. Moreover the highest $C_{p}$ for all the wind speeds tested was achieved at an rpm that is lower than the vibration point $(700-750 \mathrm{rpm})$. This therefore means that at all the rotational speeds in in tables 3 and 4; the turbine can effectively capture the targeted power from the wind within the limit of the rated rotational speed. This is a crucial factor especially considering that the turbine is designed to optimally operate within a given limit beyond which it may not withstand the loads subjected to it; a case which so often lead to fatigue and hence damage to the blades or reduced life span.

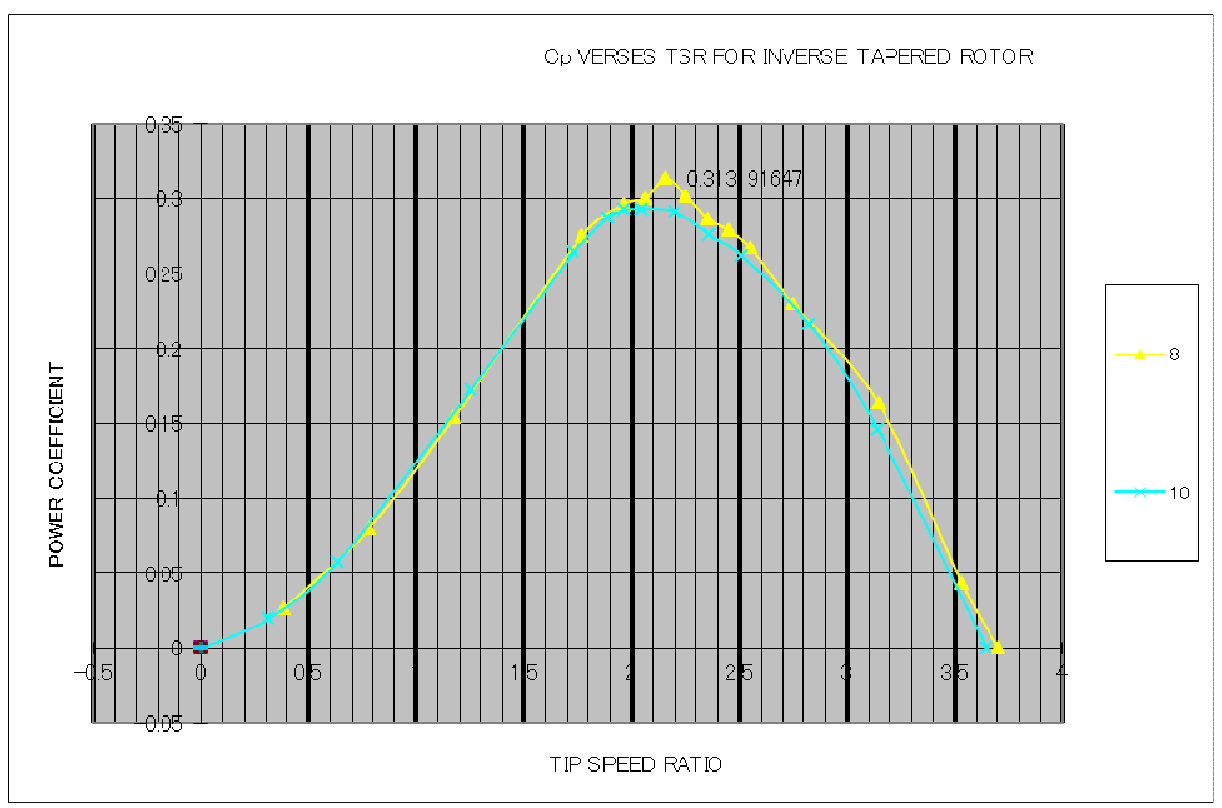

Figure 4. Coefficient of power for various TSR for the inverse tapered rotor. 


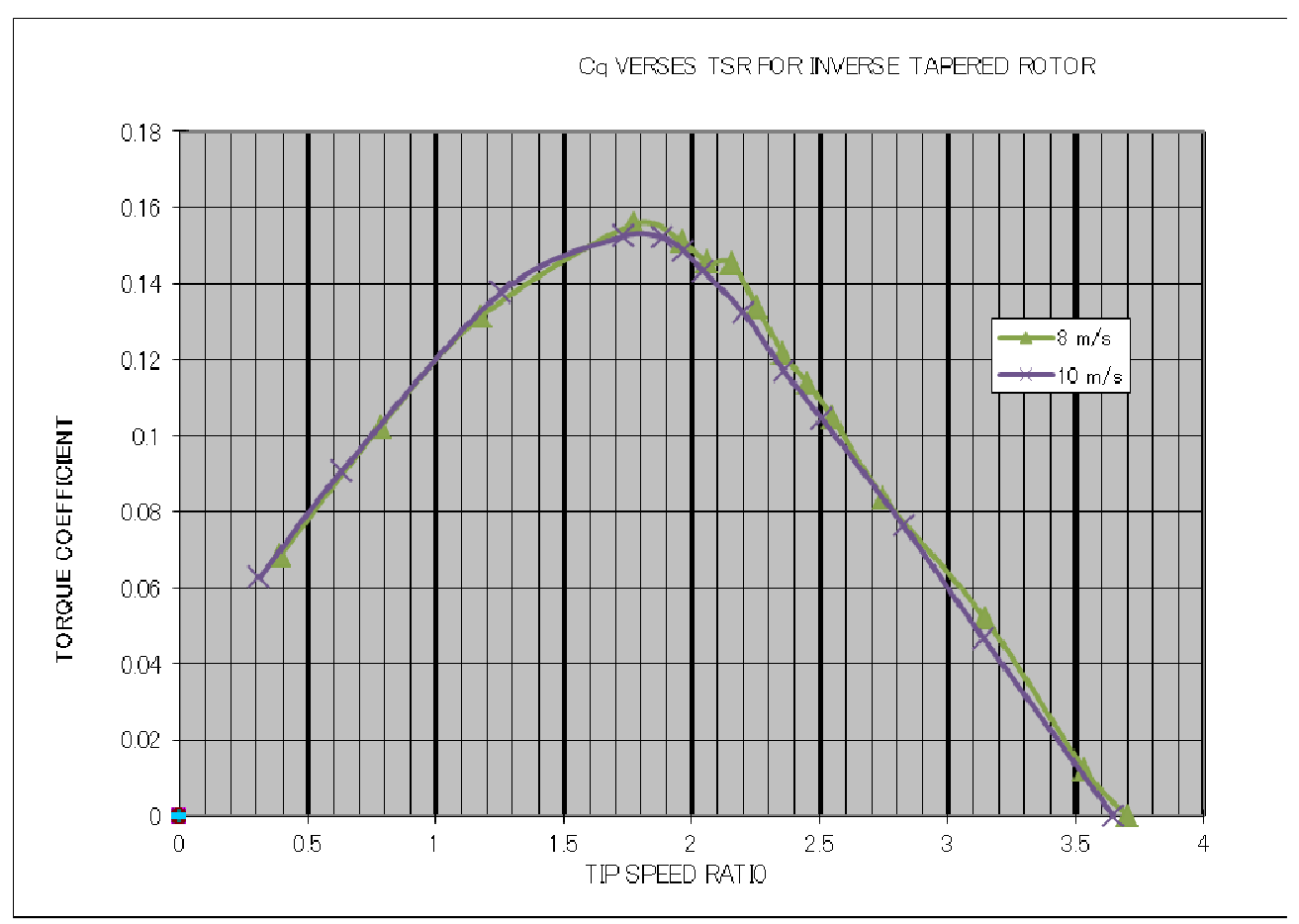

Figure 5. Coefficients of torque verses TSR for inverse tapered rotor at various wind speeds.

The torques of the turbines shown above is based on the generator as the load. At a constant wind speed, the rotor accelerates until it reaches the rotational speed that balances the load from the generator. If the rotor moves from the equilibrium point, the load restores the original. As the rotor speed increases beyond the equilibrium point, the breaking torque from the generator is higher and hence slows down the rotor. A much steeper torque curve can lead to an unstable equilibrium since there is no well-defined crossing between the torque from the rotor and the load from the generator. A high solidity turbine means a lower torque and therefore at constant $C_{P}$ the torque coefficient would be higher.

A higher tip speed demands reduced chord lengths leading to narrow blade profiles. This can lead to reduced material usage and lower production costs. Although an increase in centrifugal and aerodynamic forces is associated with higher tip speeds. The increased forces signify that difficulties will arise in maintaining structural integrity and preventing blade failure. As the tip speed increases the aerodynamics of the blade design become increasingly critical and complex because a blade which is designed for high relative wind speeds develops minimal torque at lower speeds. This results in a higher cut in speed and difficulty in self-starting. Large modern HAWT generally utilize a tip speed ratio of nine to ten for two bladed rotors and six to nine for three blades. This has been found to produce efficient conversion of the winds kinetic energy into electrical power. (Duquette et. al., 2003)

Although the data for the curves in figures 3 and 4 can also be obtained through modelling, care must be taken because the results depend heavily on the lift and drag coefficient which in turn vary as a function of the flow conditions, e.g the Reynolds number, and any slight change to it may lead to a remarkable variation on the result.

\subsection{Visualization Results}

The streamlines were drown based on the average vector (average wind speed and average angle) and were calculated at each measurement points by P.I.V. system. The streamlines obtained were as in Figure 6 , at $8 \mathrm{~m} / \mathrm{s}$. In this figure, the nondimensional axial direction and span direction are described by $\mathrm{x} / \mathrm{R}$ and $\mathrm{y} / \mathrm{R}$

Figure 6 shows the streamlines of inversely tapered rotor and it indicates that there is wind flow around area from $\mathrm{x} / \mathrm{R}=0.2$ and $\mathrm{y} / \mathrm{R}=0.2$. Thus, around root area, the inversely tapered type could extract some energy. This is the reverse case for the tapered type which from other studies of their visualization tests found that the there was no wind flow within the region state above.

A comparison of the flow angles of the tapered and inverse tapered rotors revealed more insights in the efficiency of the inversely tapered rotor. The comparison of inflow angle of each of models from the average vectors around $\mathrm{x} / \mathrm{R}=-0.2$ and $x / R=-0.4$ is shown in Figure 7. The "zero" of inflow angle defined wind direction, the angle of clockwise direction was "positive". From the figure 33, the inflow angles of tapered rotor is higher than the inverse tapered rotor in span direction at $\mathrm{x} / \mathrm{R}=-0.4$. The inflow angle difference is about $4^{\circ}$ around $y / R=0.9$. Moreover, at $x / R=-0.2$, the inflow angle of tapered type is $25^{\circ}$ and inversely tapered type is $18^{\circ}$ around $y / R=0.6$, the difference is maximum of about $7^{\circ}$. These results show that the maximum power coefficient of inversely tapered type was larger than tapered type because the inflow angle of inversely tapered type is smaller. Moreover its axial direction wind flow is stronger. Thus, inversely tapered type can extract more energy from wind. 
The visualization test also does not show any possibility of this turbine having experienced wake rotation as can be seen in the figure 31 and 32 . This therefore justifies the earlier design consideration of having the axial induction factor $a^{\prime}$ as zero. However, for large turbines this may not necessarily hold because the propeller induces a torque on the wind flow causing the wake to rotate. This swirling motion involves energy which is not captured by the propeller shaft hence it constitutes an energy loss.

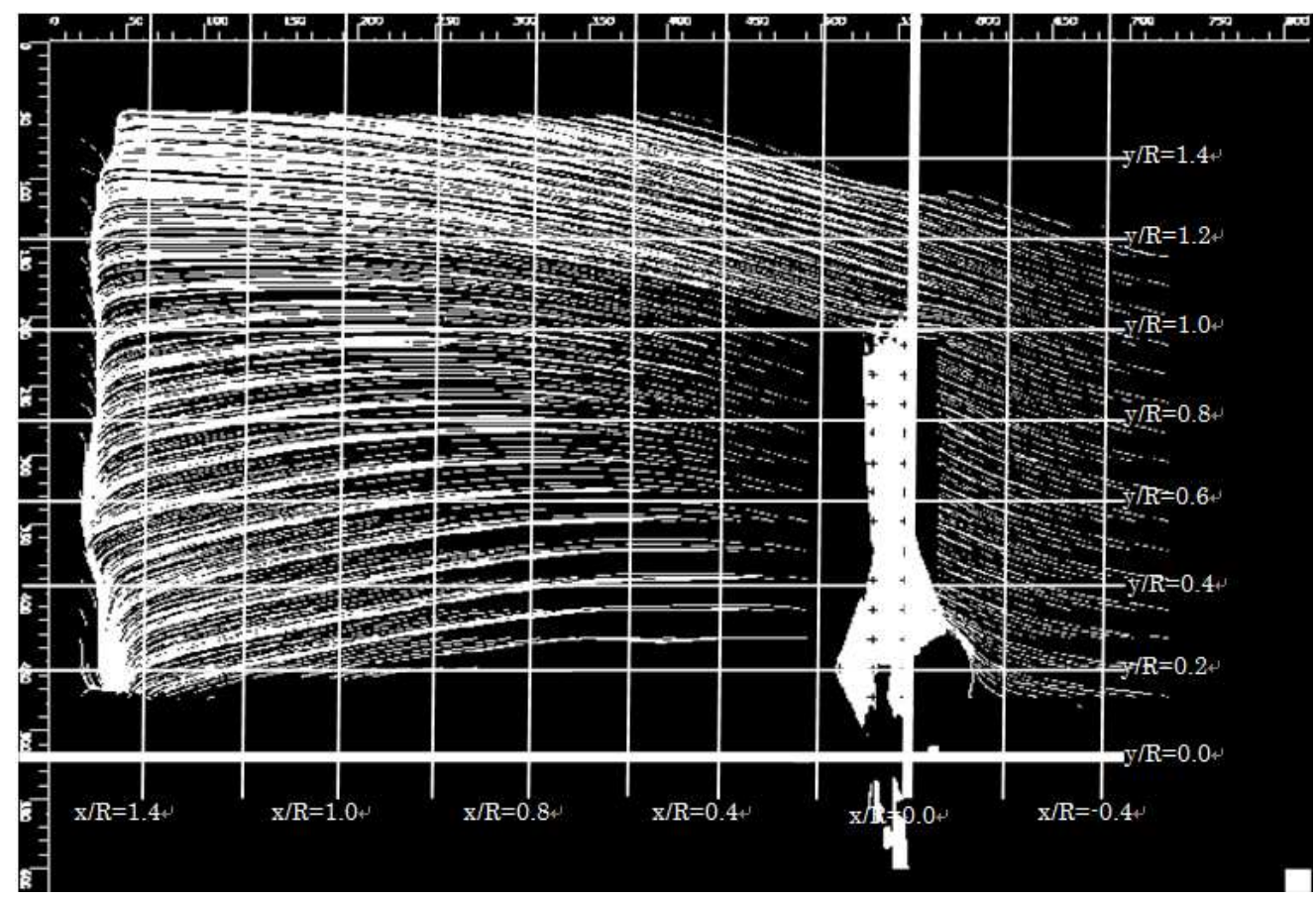

Figure 6. Streamline of inversely tapered type.

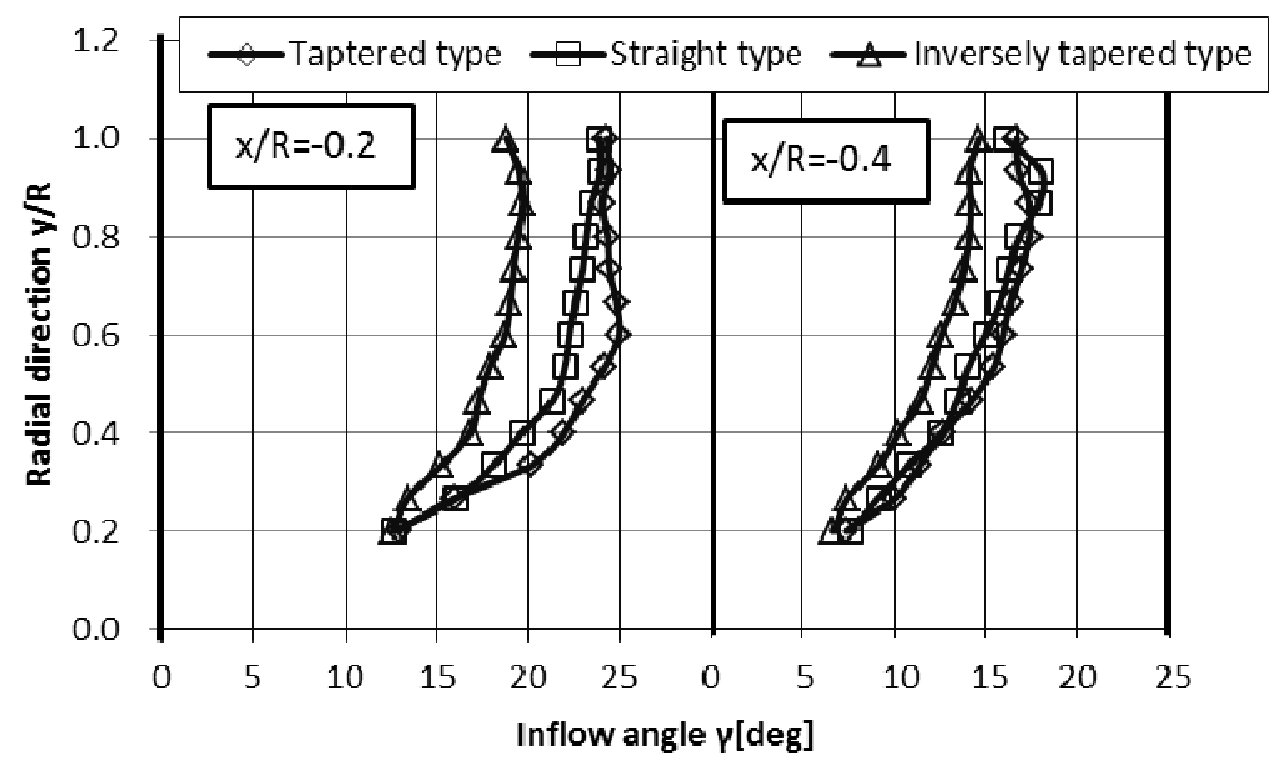

Figure 7. Comparison of inflow angles.

From the streamlines, wind mapping of axis direction were drawn for both the tapered and the inverse tapered rotor and are shown in Figures 8 and 9 respectively. The axes of the figure are; the main axis is axial direction $\mathrm{x} / \mathrm{R}$, the depth axis is span direction $y / R$ and the vertical axis is wind speed of axial direction. From figure 8 it can be seen that wind speed in the axial direction towards the root from the tip of blade reduces the velocity distribution of all blades. However, the velocity distributions of about $7 \mathrm{~m} / \mathrm{s}$ to $8 \mathrm{~m} / \mathrm{s}$ were observed to be relatively large numbers in inversely tapered type. Furthermore, it was clarified that the wind speed of inflow around the tip of tapered type is about $7.5 \mathrm{~m} / \mathrm{s}$. On the other hand, inversely tapered type was about $8.0 \mathrm{~m} / \mathrm{s}$. From these results, it can be concluded that the latter type is more effective in converting the air flow in to the shaft power than of the former type of rotor. 

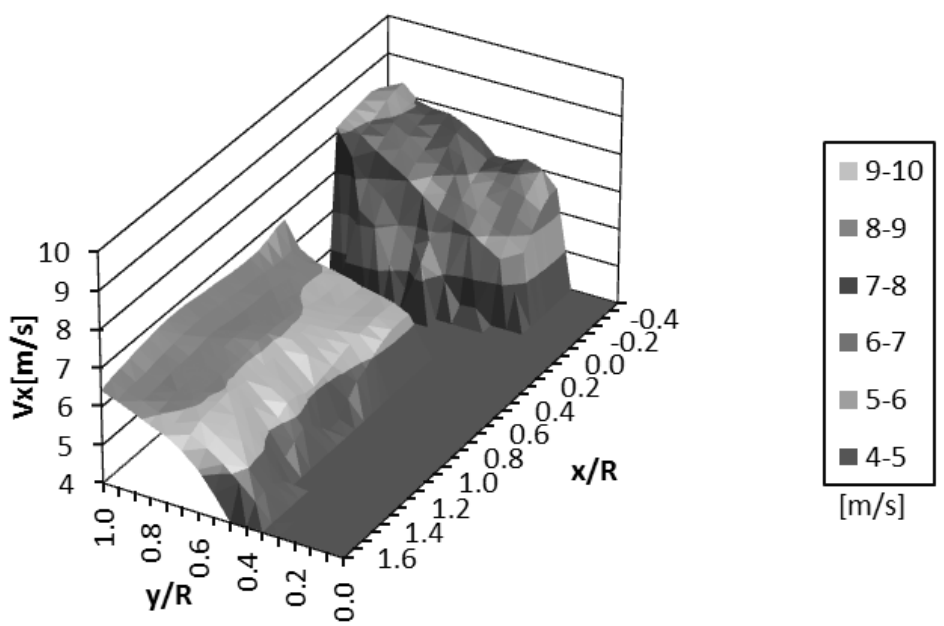

Figure 8. $V_{x}$ contour for inversely tapered type.
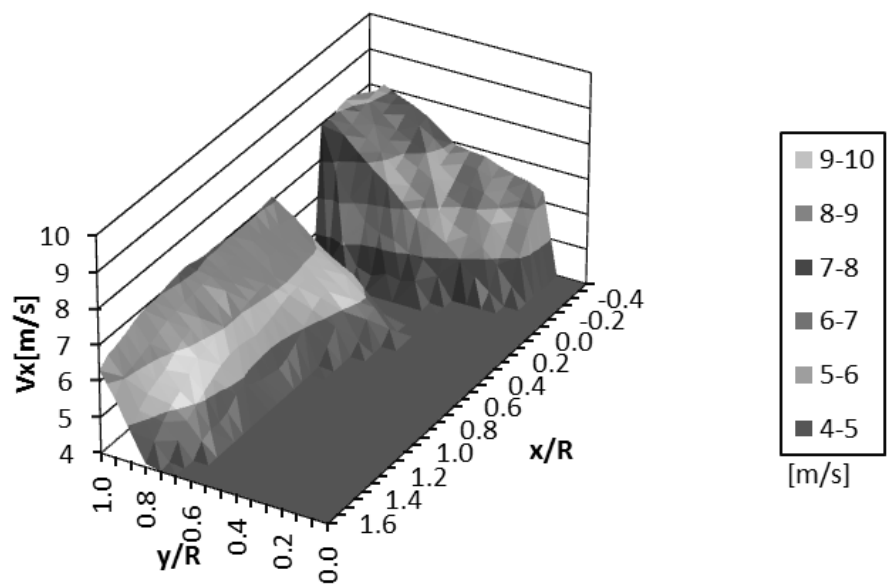

Figure 9. $V_{x}$ contour for tapered type.

\section{Conclusions}

a) The maximum coefficient of power for the inversely tapered was found to be 0.313 at $8 \mathrm{~m} / \mathrm{s}$. the inversely tapered rotor therefore has a higher power performance that the tapered rotors.

b)From the visualization test and P.I.V. analysis, it was found that wind speed inflow around tip of tapered type is about $7.5 \mathrm{~m} / \mathrm{s}$, while for the inversely tapered type was about $8.0 \mathrm{~m} / \mathrm{s}$ because of the difference in inflow angles. Therefore the later type is more effective in converting air flow into shaft power than the former type.

\section{References}

[1] K. Maeda et. al., (1995). Education for Technological History, Publishing department in Tamagawa University, pp. 108-114

[2] I. Ushiyama and T. Pruwadi, Development of a Simplified Wind-Powered Water Pumping System in Indonesia, Wind Engineering, Vol. 16, No.1, (1992(), pp.2-7
[3] I.Ushiyama, Re-evaluation of Cooperative Technology for Developing Countries Based on the History of Technology, Japan Society of Education for History of Technology, Vol.2, (2000), pp.1-9

[4] Y. Ohguro, R. Suegara, I. Ushiyama, K. Seki and H. Minami, Study of Straight Wing with Sail Type Vertical Axis Wind Turbine, Vol.26, No.1, (2002), pp.67-70

[5] E. H. Lysen, Introduciton to Wind Energy, Consultancy Servises Wind Energy Developing Countries, (1983), pp. 5673

[6] Y. Nishizawa, M. Suzuki, H. Taniguchi and I. Ushiyama, An Experimental Study of the Shapes of Blade for a Horizontal Axis Small Wind Turbines (Optimal Shape for Low Design Tip Speed of Rotor), JSME, B, Vol.75, No.753, (2009), pp.1092-1100

[7] H. Ejiri, M. Suzuki, H. Taniguchi, Y. Nishizawa and I.Ushiyama, An Experimental Study o the Shape of Rotor for Horizontal Axis Small Wind Turbine and a Wing Let, JSME, B, Vol. 77, No.776, (2011), pp.924-928

[8] Y. Nishizawa, C. Shengnig, R. Elson and I. Ushiyama, An Experimental Study on Performance of Curved- plate Blade Rotor, Renewable Energy, Vol.49, (2013), pp.6-9 
[9] I. Ushiyama, Y. Nishizawa and R.Elson, Development of Small Wind Turbine using Curved-plate Blade Rotor, Proceedings of $12^{\text {th }}$ World Wind Energy Conference (WWEC2013), (2013), pp.1-6

[10] Godfrey Boyle, et. al., Renewable Energy - Power for a Sustainable Future - Third Edition, Oxford, (2012), pp.297362

[11] Y. Nishizawa and I. Ushiyama, An Experimental Study of Horizontal Axis Sail Wing Type Small Windmills, JWEA Wind Energy, Vol.32, No.3, (2008), pp.116-121
[12] Saoke C.O., Kamau J. N., Nishizawa Y., Kinyua R., Ushiyama I., Nakajo Y., (2014). Design and Fabrication and Testing of a Low Speed Wind Turbine Generator Using Tapered Type Rotor Blade Made from Fibre Reinforced Plastic, International Journal of Sustainable and Green Energy. Vol. 3, No. 1, pp. 20-25. doi: 10.11648/j.ijrse.20140301.14 